\title{
TARDES DE ENSEÑANZA Y PARROQUIA: EL ADOCTRINAMIENTO DE LAS NIÑAS EN LA ESPAÑA FRANQUISTA A TRAVÉS DE LAS REVISTAS BAZAR Y TIN TAN (1947-1957)
}

\author{
Evenings of Teaching and Parish: The indoctrination of girls by means of \\ the magazines Bazar and Tin Tan during Franco's dictatorship in Spain \\ (1947-1957)
}

\author{
Francisco Javier Martínez Cuesta \\ José Manuel Alfonso SÁnChez \\ Universidad Pontificia de Salamanca \\ jmalfonsosa@upsa.es
}

Fecha de recepción: 22-II-2013

Fecha de aceptación: 17-III-2013

\begin{abstract}
Resumen: La presencia de la mujer fuera de la esfera privada durante el primer franquismo se redujo a dos entornos concretos: la militancia en la Sección Femenina y la pertenencia a asociaciones de signo religioso, dentro de las cuales destacó la rama femenina de Acción Católica. Sección Femenina y Acción Católica realizaron labores similares relacionadas con la formación y la asistencia socio-sanitaria, predominando el componente político en la primera y el religioso en la segunda. Desde el primer momento, ambas organizaciones generaron sus propias publicaciones periódicas pudiendo ser internas, si se dirigían a los dirigentes y militantes, y externas o dedicadas al público general. Mientras que las primeras sirvieron para formar y encuadrar a sus propios miembros, los periódicos o revistas de masas se destinaron a proyectar sus ideales políticos o religiosos e intentar captar a nuevos seguidores. Nosotros nos fijaremos en dos de ellas destinadas al público infantil femenino: Bazar, publicada por Sección Femenina, y Tin Tan por Acción Católica.
\end{abstract}

Palabras clave: Género, franquismo, Sección Femenina, Acción Católica de la Mujer, adoctrinamiento, publicaciones para niñas. 
Aвsтract: The Feminine Section and Catholic Action carried out similar work related to training as well as social and health care. The former was more political in its focus while the latter was more religious. From the very beginning both organizations created their own periodic publications, which were either internal if aimed at leaders and active members and external, if they were to be read by the general public. While the former served to train and define its own members, the newspapers and magazines for the masses were used to project their political or religious ideals and to try to recruit new followers. We will concentrate on two of them which were aimed at a young female readership: Bazar, which was published by the Feminine Section and Tin Tan, which was published by Catholic Action.

Keywords: Gender, Franco's dictatorship, Feminine Section, Women's Catholic Action association, indoctrination, publications for girls.

\section{MODELO DE MUJER EN EL FRANQUISMO}

El franquismo supuso un retorno al modelo femenino anterior, dejando de lado los conatos feministas de la década de 1930, retomando los valores tradicionales y conservadores de un catolicismo que intentó utilizar como uno de los elementos legitimizadores de su régimen. ${ }^{1}$ De ahí que, de la tentativa del periodo republicano de sacar a la mujer a la esfera pública, se pase a volver a recluirla al hogar como defendían la tradición católica y el fascismo ${ }^{2}$. Se produjo una amalgama entre la mujer sumisa, sacrificada y pura, que patrocinaba la Iglesia, y la mujer custodia del hogar y los sentimientos, y madre de los hijos, propuesta por el fascismo femenino. ${ }^{3}$

De esta manera muchos autores, en esos momentos, volvieron a hablar de la «mujer fuerte», la "muy mujer»: Poner como ideal ante nuestros ojos, no a la señorita pintada que lee novelas y va al cine, sino la «mujer fuerte» de la Sagrada Escritura ${ }^{4}$.

La Madre Oliva Reina lo sintetizó diciendo que la educación debe "hacer a la mujer muy mujer, para que sea apoyo del varón, alma de la familia, sostén de la

1 Véase ROCA I GIRONA, J., De la pureza a la maternidad. La construcción del género femenino en la posguerra española, Madrid, Ministerio de Educación y Cultura, 1996,21-26. y MARTÍN GAITE, C., Usos amorosos de la posguerra española, Barcelona, Anagrama, 2007, 26-28.

2 Para un análisis exhaustivo acerca de la participación de las mujeres en la sociedad durante el Gobierno de la II República, véase SÁNCHEZ BLANCO, L.: La educación política y social de dos organizaciones femeninas en la Guerra Civil española. Tesis doctoral dirigida por el Dr. José Manuel Alfonso Sánchez, Facultad de Ciencias Humanas y Sociales de la Universidad Pontificia de Salamanca, 2012.

3 Como señala Molinero, se trataba de la clausura forzada en un mundo pequeño. «Mujer, franquismo, fascismo", Historia social 30 (1998) 99-100.

4 SERRANO DE HARO, A., La escuela rural, Madrid, Escuela Española, 1941, 133. 
sociedad», debe ayudarle a ser muy bella, atractiva, digna, culta (apoyo al varón), fuerte y, sobre todo, muy piadosas.

La mujer ideal resultaría, pues, de la unión del modelo burgués del ama de casa y el modelo cristiano-católico ${ }^{6}$. El modelo burgués diferenciaba la esfera productiva, ámbito público, de la esfera reproductiva asociada al ámbito privado.

El modelo cristiano-católico vuelve a tomar el Génesis como referencia y recoge la sanción aplicada a la mujer por cometer el pecado original, apareciendo dos arquetipos femeninos antagónicos representados en la Virgen María y en Eva, o si se quiere en la mujer espańola, sobria, amable, espiritual y la mujer extranjera o especie de "vamp» seductora de hombres:

¿Qué de extraño tiene el que hoy, por una intuitiva y noble reacción, busque la Espańa nacional el diferenciar sus mujeres de las mujeres del otro lado, aun cuando nos llamen bárbaros por ello algunas damas descastadas y algunos frívolos extranjeros...?

Este concepto sobre el ideal de la mujer fue recogido por las organizaciones femeninas, encargadas de transmitírselo a niñas y jóvenes. La Sección Femenina de Falange nació en $1933^{8}$, y terminada la Guerra Civil asumió la formación y el encuadramiento de las mujeres espańolas. En el IV Consejo Nacional de la Sección Femenina, celebrado en Madrid en 1940, Pilar Primo de Rivera expuso a sus camaradas el servicio más apremiante de la organización: la formación total de las mujeres.

Esta educación que será completa, queremos dirigirla principalmente hacia la formación de la mujer como madre. (...) obedecemos una orden del Caudillo, quien continuamente, y cada vez que tiene ocasión de encontrase con sus Secciones Femeninas, les da la misma consigna: Salvar la vida de los niños por la educación de las madres?.

5 REINA, O., Experiencias de educación, Madrid, RAYFE, 1940, 23-30.

6 ROCA I GIRONA, J.: «Esposa y madre a la vez: construcción y negociación del modelo de mujer ideal bajo el (primer) franquismo», en NIELFA CRISTÓBAL, G., Mujeres y hombres en la España franquista: Sociedad economia, politica, cultura, Madrid, Instituto de Investigaciones Feministas, 2003, 45-65.

7 GIMÉNEZ CABALLERO, E., Los secretos de la falange, Barcelona, Yunque, 1939, 105-106.

8 Como seńalan Alfonso y Sánchez: «La mayoría de los investigadores afirma que la Sección Femenina nació en 1934, puesto que en junio de dicho año se constituyó como Sección Femenina del Partido y se aprobaron sus estatutos. Sin embargo, desde el año 1933 había empezado ya su actividad política y social». ALFONSO SÁNCHEZ, J. M. y SÁNCHEZ BLANCO, L.: «Las mujeres del Nacionalsindicalismo. Poder y rivalidad entre Pilar Primo de Rivera y Mercedes Sanz Bachiller», Revista Interuniversitaria Historia de la Educación 27 (2008) 433. Véase también GÓMEZ FERNÁNDEZ, A. B.: «La labor político-social de sección femenina durante el franquismo en Jaén», El Futuro del Pasado 3 (2012), 161-184.

9 PRIMO DE RIVERA, P., Discursos, Circulares, Escritos, Madrid, Sección Femenina de FET y de las JONS, 1943?, 26. 
Atendiendo a este discurso falangista al hombre le correspondería la misión de salvar la nación (Patria), y a la mujer la de su mantenimiento formando familias nacionalsindicalistas. Ya que como diría José Antonio: «El verdadero feminismo no debiera consistir en querer para las mujeres las funciones que hoy se estiman superiores, sino en rodear cada vez de mayor dignidad humana y social a las funciones femeninas». De esta forma, el papel social de la mujer debía limitarse a complementar la superior misión del hombre ${ }^{10}$.

Un objetivo primordial de la educación materna fue la «formación de los hijos para Dios, para España y la Falange», en la que se incluían las reglas básicas de la formación religiosa y se inculcaban a los nińos las ideas del nuevo Estado. Otro conocido texto que defendió esta doctrina oficial fue la Guia de la madre nacional-sindicalista de Mercedes Suárez-Valdés y Álvarez:

Vosotras, camaradas madres, tenéis la obligación de hacer que vuestros hijos sean buenos cristianos, para lo cual tenéis que enseñarles, tan pronto como sea posible, las siguientes cosas que el catecismo marca como obligatorias (...).

Tenéis, también, la obligación de educar y formar a vuestros hijos para España. Desarrollad en ellos un verdadero patriotismo, hacedles amar a España sobre todas las cosas de este mundo (...); que estén dispuestos a morir por la Patria ${ }^{11}$.

Se trataba de configurar un tipo de mujer ${ }^{12}$ que, por un lado, se entregara a su «misión natural» como esposa y madre y, por otro, difundiese los «ideales» de la «Nueva España» nacida de la "gloriosa revolución nacional-sindicalista».

Para la socialización política de la mujer la Sección Femenina contó con las Escuelas de Hogar y Formación, las Cátedras Ambulantes, las Granjas -Escuela y el Servicio Social.

Además de Sección Femenina, existía otra organización de mujeres que tenía un claro componente religioso: La Acción Católica de la Mujer. Surgió en 1919 impulsada por el cardenal Guisasola y se configuró como la rama femenina de Acción Católica. En la II República desempeñó un importante papel contra la política laicista y fue permitida por el régimen franquista. Durante la guerra, la rama femenina de la Acción Católica

10 Sobre el modelo y las funciones femeninas en el franquismo puede consultarse MOLINERO, C., "Silencio e invisibilidad: la mujer durante el primer franquismo», Revista de Occidente 223 (1999), 63-82.

11 SUÁREZ-VALDÉS, M., Infancia de hoy juventud de mañana, Guía de la madre nacional-sindicalista, Madrid, Aldus, 1940, 107 y 119. (Ilustración 1).

12 Con relación al papel de la mujer en el franquismo puede consultarse SCANLON, G., La polémica feminista en la España contemporánea, Madrid, Siglo XXI, 1976; JIMENEZ LOSANTOS, E., «La mujer en el franquismo», Tiempo de historia 83 (1981) 4-15. 
prestó servicios de asistencia como la recaudación del Día del Plato Único y el Día sin Postre $^{13}$. Finalizada la guerra, su cometido fundamental consistía en recristianizar a la mujer recuperando su dignidad moral, convirtiéndose en el apostolado preferido de la jerarquía. ${ }^{14}$ En los ańos de la posguerra la moralidad y el elemento religioso formaron parte del ideario y legitimación del régimen ${ }^{15}$.

La rama femenina de adultas cumplió la función de reproducir y transmitir el modelo franquista de mujer y de familia ${ }^{16}$. La organización desarrolló una labor -localizada en las parroquias- de defensa de la religión, la moral ${ }^{17}$, la familia y la caridad, atendiendo al concepto de virtud femenina del momento ${ }^{18}$.

A pesar de que desarrollaban proyectos y actuaciones similares en el campo educativo y asistencial, la existencia de la Sección Femenina no supuso una incomodidad para la Acción Católica, porque sus miembros tenían una influencia social mayor que las falangistas y compartían con ellas un mismo modelo político-religioso de mujer. ${ }^{19}$

Aun cuando el catolicismo de la Sección Femenina nunca se pusiera en duda -recordemos que el punto programático de Falange número veinticinco hace referencia a su sentido católico y que en 1939 se adopta a Santa Teresa de Ávila ${ }^{20}$ como patrona de

13 Sobre este aspecto puede verse CENARRO, Á., La sonrisa de falange. Auxilio Social en la guerra y en la posguerra, Barcelona, Crítica, 2006, 50.

14 Véase BLASCO HERRANZ, I., "Las mujeres de Acción Católica durante el primer franquismo» en Tiempos de silencio. Actas del IV Encuentro de Investigadores del franquismo, Universitat de València, Valencia, 1999, 158-163.

15 Son numerosos los textos publicados acerca de normas de conducta moral para la mujer. Véanse al respecto: ASPIAZU, J., Tú y ella, Madrid, Bibliográfica Española, 1942; GAMBÓN, V., Educación cristiana de las jóvenes, Barcelona, Pontificia Puertaferrisa, 1946; DELGADO CAPEÁNS, R., La mujer en la vida moderna, Madrid, Bruno del Amo, 1941; SARABIA, R., ¿Cómo se educan los hijos?, Madrid, El Perpetuo Socorro, 1945; VEGA, D., Las modas al ridículo, Madrid, La Milagrosa, 1945.

16 Véase NICIOLAS MARIN, Ma E. y LÓPEZ GARCÍA, B., «La situación de la mujer a través de los movimientos de apostolado seglar: la contribución a la legitimación del franquismo (19391956)» en CAPEL MARTÍNEZ, R., (coord..), Mujer y sociedad en España (1700-1975), Madrid, Ministerio de Cultura, 1982, 369-389.

17 «Apostolado pro moralidad pública (...) para el saneamiento de los cinematógrafos, teatros, playas, centros de diversión, etc., etc.», en Reglamento General de la Asociación de las Mujeres de Acción Católica. Toledo 1941,10.

18 Remitimos a ÁLVAREZ RODRIGO, Á., «La reorganización de la Unión de mujeres de Acción católica en la diócesis de Valencia (1939-1951)", en Tiempos de silencio. Actas del IV Encuentro de Investigadores del franquismo, Universitat de València, Valencia, 1999,140-145. Citado por MORENO SECO, M., "De la caridad al compromiso: las mujeres de Acción Católica (19581968)», en Historia contemporánea 26 (2003) 239-265.

19 Véase GALLEGO MÉNDEZ, T., Mujer, falange y franquismo, Madrid, Taurus, 1983, 133-160.

20 Para un estudio más amplio consultar DI FEBO, G., Di, La Santa de la raza. Un culto barroco en la España franquista (1937-1962), Barcelona, Icaria, 1988. 
la organización-, las mujeres de Acción Católica que tenían como modelo a la Virgen María -las llamadas "graciosas y adorables Cenicientas de la caridad" por la prensa falangista-, eran muy diferentes de las afiliadas de la Sección Femenina, que las tachaban de «ñoñas», antítesis del estilo y manera de ser de la Sección ${ }^{21}$.

La labor de transmisión del modelo patriarcal de sociedad no sólo le correspondió a la mujer, pues la escuela también debía colaborar en esta tarea. De ahí la importancia que se le concede a la mujer como maestra, por lo que las organizaciones tuvieron gran interés en penetrar en el Magisterio. La Sección Femenina publicó una revista dedicada a la docencia y a las maestras: Consigna $a^{22}$ y creó, como se ha señalado anteriormente, sus propias escuelas y las Cátedras Ambulantes. Acción Católica fundó el secretariado de enseñanza y organizó cursos y jornadas destinadas a las maestras y a su formación religiosa y moral, abriendo escuelas de hogar en los centros parroquiales.

Con el paso del tiempo las dos organizaciones experimentaron un proceso de evolución y adaptación a los cambios, que se tradujo en una mayor participación de las afiliadas. En Acción Católica, se pretendió que las mujeres se concienciaran de las situaciones sociales injustas y que adoptaran un compromiso personal; también sus reuniones fueron más participativas y se tuvieron en cuenta sus opiniones ${ }^{23}$. Este mismo fenómeno se observó en la Sección Femenina y en sus revistas divulgativas y programaciones radiofónicas ${ }^{24}$. Se comenzó a hablar de una creciente participación de la mujer en la sociedad: trabajo, estudios, matrimonio, etc. que reflejaba el cambio de una sociedad más moderna que iba a entrar en la década de 1960.

Para concluir se podría afirmar que la principal diferencia entre ambas organizaciones consistiría en el "componente de adoctrinamiento político en un caso, y recristianizador en el otro, así como en el colectivo sobre el que quisieron influir: jóvenes ${ }^{25}$ la Sección Femenina, casadas y adultas, Acción Católica» ${ }^{26}$.

21 Véase RICHMOND, K., Las mujeres en el fascismo español. La sección femenina de la falange, 19341959, Madrid, Alianza, 2004, 120.

22 Puede consultarse el estudio de RABAZAS MORENO, T. y RAMOS ZAMORA, S., "La construcción del género en el franquismo y los discursos educativos de la Sección Femenina», Encounters on Education 7 (2006) 43-70.

23 MORENO SECO, M., "Mujeres, clericalismo y asociacionismo católico», en DE LA CUEVA MERINO, J. y LÓPEZ VILLAVERDE, A. L., (coords.), Clericalismo y asociacionismo católico en España: de la restauración a la transición, Cuenca, Universidad de Castilla La Mancha, 2005, 126.

24 En su revista Consigna, y en Teresa, revista para todas las mujeres y su versión radiofónica: «Teresa».

25 Puede verse RODRÍGUEZ LÓPEZ, S., «Niñas y jóvenes en el franquismo», en MIR, C.(ed.), Jóvenes y dictaduras de entreguerras. Propaganda, doctrina y encuadramiento: Italia, Alemania, Japón, Portugal y España, Lleida, Milenio, 2007, 197-242.

26 GÓMEZ CUESTA, C., «Entre la flecha y el altar: el adoctrinamiento femenino del franquismo. Valladolid como modelo, 1939-1959», Cuadernos de Historia Contemporánea 31 (2009) 297-317. 


\section{LAS PUBLICACIONES POLÍTICAS Y CONFESIONALES}

Como indicamos Sección Femenina y Acción Católica realizaron publicaciones periódicas ${ }^{27}$, muchas de ellas destinadas a las jóvenes y adultas, pero también dedicaron revistas a las niñas como Bazar (1947-1970) y Tin Tan (1951-1961). Acción Católica asimismo publicó tebeos orientados a los niños: ${ }^{Z} Z$ as! (1945) y Trampolín (1949) ${ }^{28}$.

La producción de tebeos o revistas infantiles se encuadró en tres grandes apartados: los tebeos comerciales, los tebeos confesionales y los que podríamos llamar de indoctrinación política, cuya finalidad era convencer al público infantil sobre determinadas formas de comportamiento colectivo.

Aunque históricamente aparecieron primero los tebeos políticos y religiosos (Flechas 1936, Pelayos 1936, Flecha 1937, Flechas y Pelayos 1938, Colegio 1938), quienes siempre tuvieron más seguidores fueron los comerciales, tal vez porque tenían que esforzarse en conseguir el favor del público. Tanto era así que entre los modelos ideológicos puede comprobarse su mayor o menor popularidad y permanencia, según su acercamiento a los modelos comerciales y el grado en el que hubieran conseguido disimular su carácter adoctrinador.

Lo cierto es que todas estas publicaciones infantiles en cierta medida, dependiendo de su difusión, representaron en la posguerra «el factor cultural y la presencia artística más considerable de la vida del Estado Español» pasando «a ser objetivamente la representación más importante de la cultura de hecho» ${ }^{29}$.

Como ocurrió en la escuela con los textos formales dedicados a las nińas ${ }^{30}$, las publicaciones femeninas de las organizaciones se convirtieron en instrumentos de

27 La Sección Femenina editó $Y$ (1938-1946), Medina (1941-1944), Consigna (1941-1960) revista para los mandos y las maestras, Ventanal (1946-1951), Teresa (1954). Acción Católica también publicó las revistas Misión (1939-1947), Para Nosotras (1941-1965), Senda (1943-1956), Cumbres (1948-1959), Volad (1948-1963), Alba de juventud (1944).

28 Puede consultarse VÁZQUEZ DE PARGA, S., Los comics del franquismo, Barcelona, Planeta, 1980, 107-112; MARTINN, A., Apuntes para una historia de los tebeos, Barcelona, Glénat, 2000, 147-150. (Ilustración 2).

29 CIRICI, A., La estética del franquismo, Barcelona, Gustavo Gili, 1997,160.

30 Como los de Josefina Bolinaga: Mi costurero, 1951; Sólo para niñas, 1957; Ven a mi jardín, 1961; Josefina Álvarez de Canovas: Mari-Sol, inspectora, 1945; Carmelín, la niña diablillo, 1946; Federico Torres: Cartas de niñas, 1945; Oid niñas..., 1948; Mis amiguitas, 1949; Cómo se educó Carmina 1953; Antonio J. Onieva: Niñas y flores, 1946; Galería de muñecas, 1950; Florilegio de mujeres españolas 1953. Puede verse CÁMARA VILLAR, G., "El adoctrinamiento político en la escuela del franquismo: Nacional-catolicismo y textos escolares (1936-1951)», en Infancia y Sociedad en España, Jaén, Hesperia, 1983, 161-199; SÁNCHEZ-REDONDO MORCILLO, C., Leer en la escuela durante el franquismo, Cuenca, Universidad de Castilla-La Mancha, 2004; NAVARRO GARCÍA, C., "Libros de texto y lectura en las escuelas españolas (1939-1945)», en CERRILLO, P y MARTÍNEZ SORIA, C., Lectura, infancia y escuela, Cuenca, Ediciones de la Universidad de Castilla-La Mancha, 2009,101-111. (Ilustraciones 3 y 4). 
difusión del nuevo modelo ideológico y sus valores sociales, contribuyendo a establecer el ideal de mujer buscado en el franquismo. Ejerciendo, al mismo tiempo, de verdaderos órganos de propaganda en la captación de nuevas militantes y asociadas entre las filas de las Juventudes Femeninas de Falange y aspirantes de la Acción Católica. Como ejemplo de estas publicaciones se encuentran Bazar, revista de la Sección Femenina de F.E.T. y de las J.O.N.S. para las juventudes, y Tin... Tan... revista de las Niñas de A.C.

\section{BAZAR, REVISTA DE LA SECCIÓN FEMENINA DE F.E.T Y DE LAS J.0.N.S.}

En enero de 1947 apareció Bazar ${ }^{31}$ dirigida por Elisa de Lara ${ }^{32}$ (Lula de Lara) con un formato mensual de algo más de veinte páginas y un precio de 3,75 pesetas.

Los precios de la suscripción, para el primer año, fueron: 45 pesetas al año, 22,50 al semestre y 11,25 al trimestre. En la revista se animaba a que se suscribieran con anuncios como: "La revista Bazar es la mejor amiga de las niñas. Os ofrece los cuentos y las historietas más divertidas. Los dibujos más bellos, las secciones más interesantes que podéis desear. $Y$, además, grandes regalos para las suscriptoras" ${ }^{33}$. Teniendo en cuenta que no fue una revista barata, podemos deducir la clase social de las niñas que la leían.

Las portadas de los números de la primera época (1947-1950) estaban firmadas por «Serny» (Ricardo Summers e Isern), que fue el director artístico. El gran formato de la revista $(31 \times 22 \mathrm{~cm}$.) era -como señala Jaime García Padrino- «un marco espléndido para unas escenas enmarcadas por fondos de colores sólidos y protagonizadas por femeninas figuras infantiles, de extraordinaria delicadeza y suavidad en sus trazos» ${ }^{34}$. Además el diseño de las páginas y secciones interiores -que podemos atribuir a su director artístico- mostraba una gran elegancia y equilibrio. Los primeros números de la revista contaron con la colaboración de destacados escritores ${ }^{35}$ e ilustradores como: Concha Espina con «La flor de la maravilla», ilustrada por Penagos; Sofía Morales con «El niño con el

31 Véase SÁNCHEZ CARRERA, C., «Memoria y análisis de la revista Bazar (1947-1950)», en TRUJILLANO, J. M. y GAGO, J. M. (eds.), Historia y fuentes orales. "Historia y memoria del Franquismo». Ávila: UNED-Fundación Cultural Santa Teresa, 1997,121-130. (Ilustración 4).

32 Entrevistada en 1981 por Sara Palacio pensaba que el modelo tradicional de mujer, presentado por Pilar Primo de Rivera, podía seguir siendo válido: «Ni ella ni ninguna de las que trabajamos junta a ella pensamos que la mejor manera de "realizarse" para una mujer (según hoy se dice) consista en hacer cuentas detrás de una mesa de despacho o de una ventanilla, mejor que concebir..." (PALACIO, S., "La historia nos ha traicionado. Entrevista con Lula de Lara», Tiempo de historia 83 (1981), 16-23).

33 Bazar, agosto 1947, núm. 6, 2.

34 GARCÍA PADRINO. J., Formas y colores: la ilustración infantil en España. Cuenca, Ediciones de la Universidad de Castilla-La Mancha, 2004, 155.

35 Véase BRAVO-VILLASANTE, C., Historia de la literatura infantil española, Madrid, Doncel, 1963, 247-248. 
corazón de oro»; Josefina de la Maza con «La Argentina»; los cuentos de Gloria Fuertes y de Aurora Díaz Plaja, etc.

Aurora Mateos fue redactora-jefe de la revista y la creadora de Doña Sabihonda, una especie de hada oronda y bonachona que mantenía correspondencia con las lectoras, y de Guillermina, una niña inquieta y traviesa, que apareció en la sección llamada "Guillermina cuenta» dibujada por Serny. Mateos también se ocupó de divulgar la religión escribiendo historias de mujeres y hombres santos.

Aparte de las secciones de «Doña Sabihonda en...", donde el hada realizaba viajes a lo largo del mundo -una versión moderna de los antiguos textos de lecciones de cosas y de geografía-y "Guillermina cuenta», en la que la niña y sus hermanos contaban historias de su vida diaria, Bazar mantenía otras fijas de carácter informativo, didáctico e interactivo: Juventudes Femeninas, Juguemos a ser amas de casa, Tijeras, hilo y dedal, Muñecos de papel, Aprende a pintar, Consejos a las niñas, y Correo de Da Sabihonda, en algún número llamada «Doña Sabihonda responde».

La primera sección comprendía los servicios, actividades, encuentros, etc., de la organización, y es un ejemplo de la campaña de proselitismo juvenil seguida para atraer a posibles nuevas flechas. Ya en el primer número de la revista, aparecía claramente el público al que iba dirigida: afiliadas, escolares y aprendices. Encabezada por la frase de Pilar Primo de Rivera: "Estaréis alegres en nuestra compañia y en vuestras caras de niñas se reflejará la salud de vuestras almas y de vuestros cuerpos", y después de animar a conocer una Casa de Flechas, un Taller de Aprendices o a participar en Concursos Nacionales escolares, finalizaba el artículo con una imperativa pregunta: ¿Sabes que me parece que tienes ganas de afiliarte a las Juventudes Femeninas? ${ }^{36}$ Por lo que la sección cumplía con el mandato de encuadrar a las «tres masas» de afiliadas, escolares y aprendices.

En la sección: Juguemos a ser amas de casa, las lectoras podían encontrar enseñanzas de cocina, economía doméstica e higiene, encaminando así a las jóvenes para el «fin natural» del matrimonio según, el discurso falangista:

\footnotetext{
Por eso la Sección Femenina tiene que prepararlas para que cuando llegue para ellas ese día, sepan decorosamente dirigir su casa y educar a sus hijos conforme a las normas dadas por la Falange, para que así, transmitidas por ellas de una en otra generación, llegue hasta el fin de los tiempos ${ }^{37}$.
}

36 Bazar, enero 1947,núm.1,10-11.

37 Palabras pronunciadas por Pilar Primo de Rivera en el Congreso Internacional de Secciones Femeninas celebrado en Alemania, en PRIMO DE RIVERA, P., Discursos, Circulares, Escritos, Madrid, Sección Femenina de FET y de las JONS, 1943?, 88. 
Tanto los textos escolares femeninos ${ }^{38}$ como numerosos manuales de formación dedicados a la mujer-escritos por religiosos y autoras afines a organizaciones políticas o religiosas del nuevo régimen-, participaron de ese discurso respecto a la formación de la mujer como madre y esposa.

Mercedes Suárez-Valdés y Álvarez que ya había publicado en 1940 el libro titulado: Infancia de hoy juventud de mañana. Guia de la madre nacional-sindicalista, escribió en 1951 La madre ideal, donde defendía un modelo de mujer, que era resultado de una educación recibida por parte de la Sección Femenina y la Acción Católica:

En estos cursillos aprenden las muchachas, desechando ñoñerías y ridículos prejuicios, todos sus deberes morales para con sus hijos el día de mañana dentro del sacramento del Matrimonio; cómo deben conducirse en él cristianamente y, por fin, cómo deben educar y formar a sus hijos. ${ }^{39}$

El canónigo Emilio Enciso Viana sostenía que la base del hogar era la mujer: «Sin la mujer la llama del llar se apaga, la casa se torna fría, destemplada, hosca, poco acogedora; hasta repele» ${ }^{40}$. Y por lo tanto su papel es importantísimo, esencial. De ella «va a depender el bienestar familiar»:

Ella ha de cuidar que la casa esté bien organizada, para que el marido, al volver de su trabajo, la encuentre agradable, guste de estar en ella, y en las ausencias la añore; y los hijos se encuentren bien en su hogar ${ }^{41}$.

La Sección femenina editó igualmente libros dedicados a las materias de las que trataba esta sección de Bazar ${ }^{42}$. En la sección Tijeras, hilo y dedal, se presentaban trabajos de

38 Federico Torres escribió: «Hoy somos muy pequeñitas, pero mañana seremos mayores. Y cuando nos convirtamos en mujeres, será muy cómodo, agradable y económico el saber preparar nuestra comida, el saber vestir a nuestras hijas, el poder llevar las riendas de nuestro hogar» (Mis amiguitas, Madrid, Hernando S.A., 1956, 48). Y «En la casa, la mujer lo es todo. Sin ella no existiría la familia, con sus vínculos tradicionales, católicos, patrióticos. Por ello si la mujer no es buena ama de casa, el hogar se derrumba como castillo de naipes al soplo de un niño (Cómo se educó Carmina, Madrid, Hernando S.A. 1954, 89). Josefina Bolinaga hablaba de la capitana del hogar «Lo cierto es que la capitana del buque-hogar siempre es la mujer. (...) ¡Mujer capitana del buque-hogar!... Vigila... Que tu buque vaya a puerto seguro" (Yo tendré un hogar, Madrid, Victoriano Suárez, 1952, 17-18). En 1957 se publicó La mujer y su hogar de Matilde Ruiz García en Hijos de Santiago Rodríguez-Burgos. SUÁREZ-VALDÉS, M., La madre ideal, Madrid, 1951,69. (Ilustración 6). ENCISO VIANA, E., El evangelio de la madre, Madrid, Stvdivm de Cultura, 1946, 61-62.

Economía doméstica, Sección Femenina de F.E.T y de las J.O.N.S, 1954; Cocina, Sección Femenina de F.E.T y de las J.O.N.S., s.f. 
costura, trabajos manuales y se hablaba de moda. Las actividades propuestas se basaron, inicialmente, en los Modelos para Labores y Trabajos Manuales que la Sección Femenina elaboró para las Escuelas de Hogar. Hay que tener en cuenta que una actividad muy importante en la educación de las niñas de la época era la costura, por lo que se publicaron distintos textos escolares dedicados a la materia ${ }^{43}$. El más conocido fue el de Josefina Bolinaga titulado: Mi costurero. En él, la autora dedicó a las niñas las siguientes palabras iniciales:

No hay arte más bello para la mujer que el arte de la costura. Pues vamos, nińas, a coser. Pero como me consta que los dobladillos y los pespuntes viven enamorados de los cantos de las nińas, cantad mientras coséis, que esos cantos son himnos al trabajo, gorjeos del bien obrar.

Vamos a coser, niñas. ¡A coser y a cantar! ${ }^{44}$

En 1957 Bolinaga escribió Sólo para niñas, ${ }^{45}$ dedicando un capítulo íntegro a las labores. La Sección Femenina también publicó libros de Corte y Confección del sistema Martí.

En el primer número de Bazar, en la sección Muñecos de papel, apareció la «mariquita» de Guillermina con su gato Fígaro, a la que seguirían en posteriores números distintos trajes y lazos para ella y su gato. Aprende a pintar presentaba bonitos dibujos que se podían colorear con acuarela o lápices de colores.

En la configuración del mundo infantil femenino, aparte de las actividades de cocina y costura, aparecían también los juegos: el corro con sus canciones, la comba, las muñecas, etc. Enseñanzas y juegos que tenían que ver con la vuelta al papel tradicional de la mujer: una mujer de «casa», «cocina» $y$ «calceta» ${ }^{46}$.

En la sección de Consejos a las niñas, que seguidamente pasó a llamarse Lo que una niña debe hacer, se daban instrucciones sobre las conductas adecuadas e inadecuadas que tenía que seguir o evitar una niña en distintas situaciones. Venía a ser una moderna urbanidad, que volvía a mirar a los antiguos manuales redactados para las niñas ${ }^{47}$, donde

43 ANDUEZA DE SEGURA, I., El corte y la confección al alcance de las niñas, Madrid, Sociedad Editora Ibérica, 1950; DUCE RIPOLLES, F., En la clase de costura, Barcelona, A.E.D.O.S., 1956. Id., J., Mi costurero, Plasencia, Sánchez Rodrigo, 1951, 7.

45 BOLINAGA, J., Sólo para niñas, Madrid, Aguilar, 1957.

Véase RUIZ CARNICER, M. A., «Niños, hogar, iglesia. La socialización política de la mujer española», en La España de Franco (1939-1975). Cultura y vida cotidiana, Madrid, Síntesis, 2004, 92.

47 Son muchos los manuales de urbanidad dedicados específicamente a las niñas: Urbanidad para niñas, Madrid, Calleja, 1886; PASCUAL DE SAN JUAN, P., Flora o la educación de una niña, Barcelona, Faustino Paluzíe, Impresor-Editor, 1898; CODINA, J., Tratado completo de urbanidad en verso para uso de las niñas. Obra declarada de texto. Con un apéndice sobre el modo de trinchar y servir en la mesa [ $1^{\text {a }}$ ed., 1838], 21 a ed., Barcelona, Antonio Juan Bastinos, Editor, 
se indicaban los valores y virtudes que tenían que «adornar» al «bello sexo» en función de su condición femenina. En 1954 la Sección Femenina publicó el manual de Convivencia socia $^{48}$. Su autora describía minuciosamente, en clara continuidad con lo que se hacía en los manuales de urbanidad, el comportamiento que tenían que mantener las niñas en determinados lugares: colegio, calle, espectáculos, templo. Y con algunas personas: padres, abuelos, hermanos, profesoras. También se daban normas concretas referidas al orden, la higiene, la amabilidad, la cortesía, la comida, la prudencia, los saludos e, incluso, el andar.

La sección Correo de Da Sabihonda se inició en el primer número de la revista con la siguiente presentación a las lectoras:

Como dice mi nombre, yo soy muy sabihonda (...) Me podéis preguntar lo que queráis, pues de todo entiendo aunque esté mal decirlo (...) Sé de arte, de historia, de modas, de juegos y también dar consejos a las niñas que me los pidan. ¡A ver quiénes son las primeras que me escriben! ${ }^{49}$

Esta sección de correo tuvo precedentes en otras revistas femeninas. En la revista Flechas y Pelayos ${ }^{50}$, junto con El cuento de Mari-Pepa -historia destinada a las niñas-aparecía la sección ¿Qué quieres saber?, donde Mari-Pepa mantenía correspondencia con las niñas:

El personaje que pregunta a todas las niñas de España: «¿Qué quieres saber?», soy yo, Mari-Pepa. (...) que es una niña traviesa y que sabe tan pocas cosas como cualquier otra nińa, podrá contestar a todas vuestras preguntas mediante la gran sabiduría que en su libro acumularon durante siglos, los tres sabios más grandes del mundo: Lepe, Lepijo y su hijo ${ }^{51}$.

Como puede verse el mensaje que se trasladaba a las niñas en las dos presentaciones era el mismo, se aceptaban todo tipo de preguntas para abarcar el mayor número de comunicantes.

1905; PASCUAL DE SAN JUAN, P., Resumen de urbanidad para las niñas, Barcelona, Hijos de Paluzíe, Editores, 1920. Edición Facsímil: Editorial Maxtor, Valladolid, 2002.; Cartilla moderna de Urbanidad (niñas), por F.T.D. [Frère Théophane Durand], $3^{\mathrm{a}}$ ed., Barcelona, Editorial F.T.D., 1929; La buena Juanita, Madrid, Calleja, s.f. Para ampliar la información de los manuales de urbanidad, puede verse: GUEREÑA, J. L., El alfabeto de las buenas maneras Los manuales de urbanidad en la España contemporánea, Madrid, Fundación Germán Sánchez Ruipérez, 2005.

WERNER, C., Convivencia Social (Formación Familiar y Social), Madrid, Sección Femenina de F.E.T. y de las J.O.N.S., [1 a 1954], 1957.

49 Bazar, enero 1947, núm.1, 18.

50 Revista que aparece el 11 de diciembre de 1938, fruto de la fusión de las revistas Pelayos (1936) y Flecha (1937).

51 Flechas y Pelayos, 11 de diciembre de 1938, núm.1, 22. 
La revista Mis Chicas $^{52}$ también mantuvo una sección de correo con sus pequeñas lectoras. En este caso se trataba de la Carta de la tía Catalina:

Os quiero mucho, os admiro, me gustan vuestras charlas, vuestras risas, vuestras preguntas y, a veces, vuestras travesuras (...) una cartita a la tía Catalina y se os resolverán todos vuestros problemas por difíciles que os parezcan ${ }^{53}$.

Esta sección de correspondencia tuvo gran peso en las revistas y, aunque no pueda considerarse un equivalente al «editorial»-como logró ser en el caso de Mis chicas-, si nos permite estudiar los comportamientos estimulados y censurados a las nińas en esa socialización informal. En Bazar estos cánones se vieron muy reforzados, como analizaremos, por la existencia de la sección llamada Lo que una niña debe hacer. La correspondencia hacía posible que las nińas accedieran paulatinamente al mundo de las mujeres; un mundo en el que primaba lo íntimo, lo afectivo, la familia y donde las preocupaciones se centraban en lo doméstico y lo estético configurando un determinado modelo de mujer.

Un modelo que primaba la formación no sólo como «ama de casa», sino como futura madre, por lo que la figura de la muñeca adquiere un significativo papel en la educación del sentimiento maternal y en la preparación para los cuidados y labores maternas. Tenemos que recordar que la Sección Femenina realizaba Talleres específicos de muñecas. Las revistas no fueron ajenas a esa importancia y muchas de ellas tuvieron su muñeca «oficial» ${ }^{54}$, y algunas secciones dedicadas a la fabricación de muñecas, casas de muñecas, confección de vestidos, etc. ${ }^{55}$.

La Sección Femenina no sólo utilizó los desfiles, exposiciones, exhibiciones, concursos y la publicación de revistas como medio de propaganda; también aplicó un poderoso medio de comunicación como la radio, que le permitió difundir su mensaje de una manera mucho más amplia a la población femenina.

52 Aparecida en abril de 1941, fue la primera revista comercial de historietas con secciones y contenidos varios, específicamente destinada a las niñas, hasta que apareció en 1948, Volad. Véase GASCA, L., Los comics en España, Barcelona, Lumen, 1969,139-140; RAMÍREZ, J, A., El «comic» femenino en España, Madrid, Cuadernos para el diálogo, 1975, 27-38.; MARTÍN, A., o. c, 144-146. Puede consultarse un estudio de la revista Mis Chicas en CARRENO, M., "Chicas en la posguerra. Un análisis sobre el aprendizaje de género más allá de la escuela», Historia de la Educación 22-23, (2003-2004) 79-104.

Mis Chicas, año 1, núm.2, 1941, 2.

54 Mari-Pepa tuvo su muñeca llamada Mari-Pepa Mendoza, con un completo ajuar. La revista Mis chicas, las muñecas Mariló y Anita Diminuta. La revista Bazar, aunque no tuvo una muñeca propia, realizaba concursos premiados con conocidas muńecas de la época (Mariquita Pérez y su hermano Juanín). Tin... Tan... sí la tuvo, se llamaba Teresín, y las niñas podían mandar historias de su muñeca a la sección llamada Travesuras de mi Teresin (Ilustración 7).

55 La revista Bazar tenía la «mariquita» de Guillermina, con una primera muñeca maniquí, aparecida en 1947 en su número 1, y otra nueva muñeca en el número 46 de 1951. 
No podemos olvidar que la radio se convirtió en la década de 1940 en «uno de los instrumentos de socialización de las mujeres de mayor alcance, tanto por los espacios de audiencia que genera como por los propios mensajes transmitidos" ${ }^{56 .}$ Teniendo en cuenta esto, la Sección Femenina realizó emisiones radiofónicas en revisatas como Ventanal y Bazar $^{5}$.

Después de una primera época (1947-1950), donde Bazar tuvo un marcado carácter político-propagandístico, con el paso del tiempo fue moderando ese mensaje para tratar de acercarse a lo que ofrecía, en esos años, una revista comercial para niñas ${ }^{58}$.

\section{TIN... TAN... LA REVISTA DE LAS NIÑAS DE A.C.}

Es probable que la revista Tin... Tan... ${ }^{59}$ naciera en mayo de 1951. En estos primeros años tuvo un formato de cuaderno grapado con portada en color o a dos tintas y páginas interiores en blanco y negro, que se alternaban con otras a dos tintas. Inicialmente fueron verticales y tuvieron ocho páginas, pero pronto se convirtieron en apaisados a la vez que aumentaron su número de páginas, primero a dieciséis y después a veinte, llegando a alcanzar las veinticuatro en números bimensuales. En esta primera época no aparece el precio marcado en la revista; en su año VIII (1958) la revista costó

56 Véase AGULLÓ DÍAZ, C., "Azul y rosa: franquismo y educación femenina», en MAYORDOMO, A. (coord.), Estudios sobre la politica educativa durante el franquismo, Valencia, Universitat de València, 1999, 264-265.

57 En 1953 la Sección Femenina vallisoletana comenzó la primera emisión de la revista radiofónica Ventanal. Semanalmente, los jueves durante diez minutos se ofrecían noticias, consejos, premios etc., a las mujeres de España. Véase GÓMEZ CUESTA, C., «La Sección Femenina y su modelo de mujer: un discurso contradictorio", en ÁLVAREZ, A., El siglo XX: balance y perspectivas, Cañada Blanch, Valencia, 2000, 200-202. En 1948 en la sección Juventudes de la Sección Femenina de Bazar se informaba de que la revista celebraba emisiones de radio quincenales, dedicadas a las niñas, donde intervenían $D^{a}$ Sabihonda, Guillermina y la rata Blanquita relatando viajes, contando cuentos y haciendo concursos (Bazar, febrero 1948, núm.11, 11 y (anuncio) Bazar, febrero 1949, núm. 23, 14).

58 La revista Bazar sufrió distintos cambios en cuanto a formato, precios, contenidos y periodicidad: Tamańo: 31 x $22 \mathrm{~cm}$. Precio: 3,75 pts. Contenido: marcadamente político. Periodicidad: Mensual; Tamaño: 28 x $20 \mathrm{~cm}$. Precio: 3,50 pts. Contenido: pierde el título inicial Sección Femenina de F.E.T. y de las J.O.N.S y secciones políticas. Periodicidad: mensual; Tamaño: $25 \times 18 \mathrm{~cm}$. Precio: 2,50 pts. Contenido: semejante al de revistas comerciales de nińas Periodicidad: semanal. El subtítulo también sufre modificaciones: Bazar en portada con el subtítulo de revista de la Sección Femenina de F.E.T. y de las J.O.N.S. en el interior; Bazar en portada desapareciendo el subtítulo de revista de la Sección Femenina de F.E.T. y de las J.O.N.S. en el interior; Bazar con el subtítulo de Revista para niñas en portada. Todos estos cambios se producen a lo largo de la vida de la revista marcando distintas etapas diferenciadas que podrían corresponder, de manera no rígida, a los siguientes ańos (1947-1950) (1951-1957) (1958-1963) (1963-1970).

59 El nacimiento exacto de la revista es difícil de fijar puesto que de estos primeros ańos hemos tenido acceso a muy pocos ejemplares. Por el material del que se dispone, esta primera época se iniciaría en mayo de 1951 y finalizaría en diciembre de 1953. (Ilustración 8). 
3 pesetas. Fue editada por el Consejo Superior de las Juventudes de Acción Católica y tuvo, lógicamente, censura eclesiástica ${ }^{60}$.

Tin... Tan... apareció como una revista destinada a las nińas y así puede verse en el anuncio de uno de sus almanaques, que enumeraba las revistas editadas y sus destinatarios:

«TIN... TAN... para las niñas, TRAMPOLÍN para los chicos, VALENTIN para niños y niñas, VOLAD para chicas jovencitas, CUMBRES para jóvenes. Y para los mayores AMBIENTE, LA ACTUALIDAD ESPAÑOLA, YA, INFORMACIONES, ECLESIA, SEN$D A \ldots{ }^{61}$.

De igual modo se animaba a que las niñas se suscribieran con anuncios ilustrados en sus páginas: "La suscripción a Tin... Tan... sólo cuesta DOCE PESETAS al año y tendrás todos los meses el periódico de niñas más bonito de España» ${ }^{62}$.

Si bien es cierto que la revista Volad ${ }^{13}$ nació antes que Tin... Tan..., ésta estuvo destinada a chicas estudiantes, adolescentes, de catorce o quince años -de hecho pronto apareció con el subtítulo Revista de las muchachas inteligentes-. Por lo que las niñas menores no tenían cabida en ella, como sí sucedió con la revista Bazar, que podía tener lectoras de cinco a dieciséis años.

Los números de la primera época de Tin... Tan...-con sólo ocho páginas- se limitaban a tener alguna sección de concursos, componiéndose de cuentos, historias y narraciones escritas por los redactores o enviadas por nińas colaboradoras.

\section{MODELO DE MUJER}

Asumiendo el modelo familiar patriarcal en el que la autoridad descansaba en el hombre, mientras que la mujer "estaba sujeta» y dependía de éste, tanto la Sección Femenina como Acción Católica, consideraban que el papel que debía desarrollar la mujer se circunscribía al hogar y al cumplimento de las llamadas tareas domésticas. Por lo que los

60 Ya que incluso una revista no confesional como Mis Chicas tuvo censura eclesiástica.

61 Almanaque Tin... Tan..., 1955, 6.

62 Almanaque Tin... Tan..., 1955,14.

63 Editada por la Delegación Nacional de Aspirantes de Acción Católica reapareció, después de la guerra, en enero de 1948. Dirigida por Pilar Santa Olalla tuvo como colaboradores a religiosos como E. Enciso y a escritoras como Carolina Toral y Monserrat del Amo, que también colaboró en la revista Alba. La revista incluía consejos acerca del comportamiento de la joven cristiana en distintos ámbitos, pequeńas historias, decoración, recetas de cocina, juegos, pasatiempos y concursos. (Ilustración 9). Véase también URIA RÍOS, P., En tiempos de Antoñita la fantástica, Madrid, Foca, 2004, 24. 
desvelos de esta mujer-esposa-madre se debían centrar en los hijos, el marido y la casa ${ }^{64}$. Se concedía tanta importancia a esa función familiar y maternal que ambas organizaciones celebraban el día de la Madre y la semana de la Madre.

El discurso de la maternidad, relacionado con ese «reino» $\mathrm{o}$ «buque» que representaba el Hogar, será esgrimido como misión primordial y fin último al que debía aspirar la mujer.

La inflexible división de los papeles masculino y femenino en la sociedad que les asignaba el ámbito público o privado para desarrollarse como persona, se ve reflejado igualmente en las publicaciones del Consejo Superior de las Jóvenes de Acción Católica. Por ello, en un capítulo de uno de sus textos podemos leer:

\section{«LA MADRE ES LA CREADORA DE LA CULTURA FAMILIAR ASÍ COMO EL HOMBRE LO ES DE LA PÚBLICA».}

El centro de la familia, sucesora de esa Familia Sagrada, es la madre. En torno a ella gira todo en la familia. El padre vive una vida de ir y venir y traer a la familia lo que puede para mejorarla. (...) Así vemos cómo en la madre culminan las perfecciones de la mujer; es el momento cumbre de las funciones naturales de la mujer como hija, novia y esposa. Es la grandísima aportación de la mujer a la cultura ${ }^{65}$.

Para cumplir con ese fin y ser una buena madre y esposa era necesaria la formación. Al igual que la Sección Femenina, Acción Católica establece sus Escuelas de Hogar en los centros parroquiales ${ }^{66}$.

Alguno de los contenidos de esa educación para el hogar lo podemos rastrear en los manuales de Economía Doméstica de la época. Se impartían nociones sobre alimentación, higiene personal, del vestido y de la casa, medicina y puericultura elemental; recetas de cocina básicas para poder hacer comidas diarias y postres (repostería). y cuestiones que tenían que ver con Avicultura, Cunicultura y la Huerta. Al hablar de las cualidades que debía tener el ama de casa se citaban las siguientes: amar el orden, amar la actividad, ser económica, saber guisar, ser previsora, ser instruida (aprender algo nuevo que sea beneficioso para el desempeńo de sus obligaciones), tener un carácter alegre ${ }^{67}$. Todos

\footnotetext{
64 Véase ROCA I GIRONA, J., De la pureza a la maternidad..., 274-288.

65 Nosotras somos así..., Madrid, Consejo Superior de las Jóvenes de A. C., 1945, 86-98.

66 Una de las actividades específicas de la Asociación de las Mujeres fue el «Apostolado de economía doméstica, fundando y sosteniendo escuelitas de labores domésticas", en Reglamento General de la Asociación de las Mujeres de Acción Católica, Toledo, 1941, 10.

67 Tomado de Hogar, Manual de Economía doméstica, Barcelona, Consejo Superior de las Jóvenes de A. C., s. f.
} 
estos contenidos no diferían de los que se podían encontrar en los textos de Sección Femenina ${ }^{68}$.

Pero no era únicamente a través de los textos «oficiales» de la organización como se propagaba ese modelo de mujer «ama de casa». También las revistas dedicadas a las niñas y jóvenes ayudaron, de manera no formal, en esa misma labor con sus editoriales, secciones, concursos y colaboraciones.

\section{LAS REVISTAS}

En las revistas femeninas de Acción Católica ${ }^{69}$ aparecían usualmente secciones dedicadas al hogar, como las de cocina o labores. Los primeros números de las destinadas a las adultas (Senda, Cumbres), que nacieron con formato de «boletín informativo", se fueron acercando con el paso de los números al de las revistas femeninas comerciales.

Ese modelo tradicional de mujer quedó patente en las informaciones, historias, secciones y colaboraciones de las revistas. Uno de los colaboradores fue E. Enciso ${ }^{70}$, que escribió en la revista de adultas Cumbres y en Volad.

En uno de sus artículos presentaba el siguiente argumento contra la mujer:

Dios creó a la mujer para ser la ayuda del hombre. Estas ‘̇a qué le pueden ayudar? A caer como Eva. En el mismo paraíso, donde debía haberle ayudado a ser feliz le ayudó a ser desgraciado. ¡Vaya faena que nos hizo!. Las que nos hacen las que ahora se empeñan en obrar como ella ${ }^{71}$.

68 La Sección Femenina editó los libros: Economía Doméstica, Madrid, Sección Femenina de F.E.T. y de las J.O.N.S., 1954; Nociones de Puericultura, Madrid, Sección Femenina de F.E.T. y de las J.O.N.S., 1954; Cocina, Sección Femenina de F.E.T. y de las J.O.N.S., s. f.; Manual de decoración, Sección Femenina de F.E.T. y de las J.O.N.S., s. f.

69 La revista Para Nosotras (1941-1965), tuvo secciones de recetas (Hogar o Cocina), noticias curiosas (En broma y en serio), confección y labores (Tareas de mujer), y $A$ casarse tocan, en la que se hablaba del matrimonio canónico. Volad (1948-1963) mantuvo secciones de cocina con recetas (Fichero de cocina Volad), en ocasiones labores (Del hilo y del ovillo) y modas; y una de pasatiempos con un significativo título (...Y la casa sin barrer); en enero de 1955 comenzó una sección dedicada a las profesiones (Escaparate de profesiones). Alba de Juventud (1948) contó con secciones de moda, cocina (Recetas de nuestras lectoras), actividades domésticas (Hay una mujer en la casa). Senda (19431956) tuvo pequeñas secciones de Modas, Labores y buenas maneras para las mujeres de A. C. (Página de Hogar). Cumbres (1948-1959) presentó secciones de moda (Orientaciones de la moda), moral de la mujer de A. C. ('Qué dirías tú!), pasatiempos (Que te diviertas). Como Alba tuvo un sección llamada Hay una mujer en la casa.

70 Como se ha señalado, E. Enciso escribió distintos libros para las jóvenes como La muchacha y la pureza, Madrid, Stvdivm, 1954 y Para tus quince años, Madrid, Stvdivm, 1959.

71 ENCISCO, E., «Muchachas con cabeza de plástico», Volad (marzo 1959) 3. 
Igualmente siguió insistiendo, desde la revista, en la idea del pecado y la pureza:

Te inquietas. Tú quieres ser buena. Tú deseas ser fiel a Jesús y no manchar tu alma pura con salpicaduras sucias. No, tú no quieres esos pensamientos (...) El que te vengan pensamientos feos no es pecado. El pecado está en que, a sabiendas, te entretengas con ese pensamiento y, más aún, si en él te recreas ${ }^{72}$.

Otra de las preocupaciones de las revistas fue la educación de las «buenas maneras» de las niñas y jóvenes, por lo que tenían secciones dedicadas a tal fin ${ }^{73}$. Bazar tuvo -en los primeros años- una, llamada Lo que una niña debe hacer, donde se indicaban aquellas actitudes y conductas consideras propias de una niña bien educada. Las virtudes en las que se hacía hincapié eran las de la obediencia, modestia, el respeto a los demás, saludos, visitas, puntualidad, etc.

Ves a mamá que está apurada con tanto quehacer. Tiene que cuidar a tus hermanos pequeños, repasar la ropa, vigilar la cocina. Tú ya eres mayorcita y puedes hacer muchas cosas en la casa. Ofrece tu ayuda ${ }^{74}$.

Tin... Tan... no tenía sección específica, pero dedicó espacios con esta intención, y en muchos de sus cuentos e historias aparecía de manera implícita esta educación:

Desde pequeñita debes ser la ayuda de mamá; procura entretener a los hermanos pequeńos dejándoles tus cuentos y revistas. ¡Pero ten cuidado que, como son pequeños, te las pueden estropear! $!^{75}$.

Un lugar en el que la niña debía demostrar sus buenos modales era en la mesa:

Ves que Juanita habla con la boca llena, que hace ruido al masticar, que sorbe la sopa, que mueve el tenedor igual que una lanza, que parte el pan a mordiscos y bebe sin limpiarse los labios (...) Ya sabes que la verdadera corrección se demuestra en la mesa $^{76}$.

$\overline{72}$ ENCISCO, E., «Sin que me preguntes, te contesto», Volad (agosto 1959) 2.

73 Las revistas para jóvenes también tuvieron estas secciones. Volad incorporó en 1945 El arte de bien vivir, y la revista Alba de Juventud la de Personajes de tu vida.

74 «Lo que una niña debe hacer», Bazar, enero 1947, núm. 1, 14.

75 «Todos los días», Almanaque Tin... Tan..., 1954, 4.

76 «Lo que una niña debe hacer», Bazar, octubre 1947, núm. 8, 15. 
La buena educación se demuestra de muchas maneras, sobre todo en la comida. Una niña bien educada no come nunca con ansia, como si estuviera hambrienta; lo hace despacio y usando bien todos los cubiertos ${ }^{77}$.

El comportamiento en las visitas y los saludos fueron igualmente tenidos en cuenta en estas secciones:

Ha llegado una visita y mamá te llama para que salgas a saludarla. Tú te niegas, quieres esconderte, te pones excitada, lo mismo que si el seńor o la seńora que está en la sala te fuera a comer. (...) Una niña asustadiza y huraña no puede luego ser una persona agradable ${ }^{78}$.

Lo mejor, pues, es, cuando sois jóvenes y así en general, enseñaros y deciros también los saludos tienen sus fórmulas de educación, según la categoría, la edad, la condición de la persona a quien se saluda ${ }^{79}$.

La pereza y la falta de puntualidad eran otros defectos que debía eliminar una joven bien educada:

Si das media vuelta cuando llega la hora de levantarte. Después vas deprisa y corriendo, a medio lavar y peinar, mientras tu madre se disgusta por tu pereza. (...) Y luego, de tanto apuro, llegarás tarde $\mathrm{al}$ «cole» $\mathrm{y}$ te pondrán de cara a la pared ${ }^{80}$.

La incorrección y descortesía que representa la falta de puntualidad, tiene mayor importancia, según la categoría de la persona de quien se trata. Así, hacer esperar a una amiga tiene más disculpa que hacer esperar a una persona de edad y respeto $^{81}$.

En las secciones también se contestaba a la antigua pregunta de las cartillas de urbanidad para niñas: ¿Cómo se porta la niña bien educada en la calle?

\footnotetext{
77 «Todos los días, Almanaque Tin... Tan...», 1954, 4.

78 «Lo que una nińa debe hacer», Bazar, agosto 1947, núm. 6, 7.

79 «Los saludos», Volad, septiembre 1954, núm. 99, 24.

80 «Lo que una nińa no debe hacer», Bazar, marzo 1949, núm. 24, 6.

81 «La puntualidad», Volad, noviembre 1954, núm. 101, 17.
} 
Para evitar sustos, vete por la calle atenta a lo que ocurre a tu alrededor y sin pensar en las musarañas; no te detengas en grupos a hablar con personas desconocidas; no corras, ni cantes, ni rías estrepitosamente ${ }^{82}$.

En la revista Tin... Tan... incluso las propias niñas contribuían a fomentar esta educación de las «buenas maneras», pues las niñas participantes mandaban historias cuyas protagonistas tenían que ser obedientes, no replicar a los padres, maestros y superiores, y ser buenas y caritativas ayudando a los más desfavorecidos. Por ejemplo, El regalo de los reyes magos cuenta cómo la pequeña Vilna, huérfana, vivía con su tía que era muy mala. Se acercaba el día de los Reyes y le decía a su tía que escribiera una carta para pedirles una muńeca:

-No la esperes -le contestó la tía-; tú lo que tienes que hacer es trabajar.

Pero un paje de los Reyes le puso la muńeca en la ventana.

-¡Dios mío gracias! ¡Qué muñeca tan bonita! ¡Gracias, buenos Reyes, qué contenta estoy!

Cuando la tía salió a la calle, ella se puso a jugar con su muñeca, y de pronto llamó a la puerta una nińa pordiosera, y después de dar a la pobre niña su desayuno, mientras lo tomaba se fijó en su muñeca.

-iQué preciosa es! -dijo-. Yo nunca tuve una muñeca. ¿¿Me la dejas dar un beso? (...)

- Oye tengo una idea! Te la regalo. Al año próximo les pediré otra a los Reyes.

Y marcha la niña muy contenta, y Vilna quedó triste sin su muñeca, pero alegre por la buena obra que había hecho. Cuando volvió su tía y vio que había regalado la muñeca le pegó y la echó de casa, pero una señora muy rica que lo vio todo la llevó a su casa en recompensa del buen corazón que tenía la niña ${ }^{83}$.

En otras ocasiones, aunque el personaje cometiera algún «pecado» siempre podía arrepentirse:

Érase un niño que vivía en una hermosa casa de las afueras de la ciudad. En el jardín tenía un estanque con preciosos cisnes y blancos patitos, con los que jugaba como buenos amigos. Pero un día cuando el niño salió al jardín a jugar con sus amiguitos del estanque, vio con gran pena que el perro había matado a todos; el pobrecito niño no sabía qué hacer y se puso a llorar; el perrito, viendo la tristeza de su amo, quedó arrepentido de la fechoría y arrepentido iba detrás de él ,procurando consolarle ${ }^{84}$.

\footnotetext{
82 «Lo que una niña debe hacer», Bazar, febrero 1948, núm. 11, 14.

83 «El regalo de los Reyes Magos», Tin... Tan..., III época, núm.1, enero 1955, 8.

84 «Cuento», Tin ... Tan...,II época, núm.7, julio 1954,16.
} 
Y también podían soñar las niñas con un príncipe que premiara con una boda su bondad y virtud, como ocurría en la colaboración enviada por una de ellas, titulada La primera encajera:

Una vez, había un rey muy sabio que deseaba dejar la corona a su hijo, y le encargó recorriese el reino para que buscase una mujer digna de ser reina por su bondad y talento. (...) después de recorrer hasta el último rincón del reino, se presentó al rey y le dijo que había encontrado una joven que, además de ser muy virtuosa, era una verdadera artista tejiendo (...) El rey le preguntó qué hada le había enseñado, y la joven, arrodillándose ante el rey, contestó humildemente: -Señor, soy huérfana y pobre, y este vestido que admiráis no es otra cosa que unos sencillos remiendos hechos con paciencia en las pobres ropas heredadas de mi madre. Sólo he tenido por maestra la necesidad. (...) la primera encajera del mundo llegó a ser reina por su virtud, paciencia y primor en el encaje ${ }^{85}$.

O en la llamada El corderito blanco, en el que a una nińa pastora huérfana muy pobre se le apareció la Virgen y le regaló un corderito blanco al que cuidó cariñosamente:

Un día, cuando fue mayor se encontró con un pastor que era un príncipe y se casó con ella y se llevaron al corderito, que ya era mayor también, al palacio y le compraron un cascabel de oro y fueron muy felices ${ }^{86}$.

Tin- Tan también contó con una sección de correo llamada Correo de tía flora -título que nos recuerda la Carta de la tía Catalina de la revista Mis Chicas-donde las niñas mandaban su correspondencia para contar sus experiencias, hacer preguntas, enviar cuentos o participar en concursos. La revista no tuvo una sección especifica dedicada a la preparación de las niñas como «amas de casa», como ocurrió en Bazar, pero en muchas de las colaboraciones se insistía en que las niñas debían ayudar a las mamás y cuidar de sus hermanos, abuelos, animales o plantas. Y, además, se les animaba a que compraran la muñeca $\operatorname{Teresin}^{87}$ con la que podían entrenarse en los deberes propios de una madre.

85 «La primera encajera», Almanaque Tin... Tan..., 1954,22.

86 «El corderito blanco», Tin-Tan, ańo VIII, mayo 1958,14.

87 «El mejor regalo y el que más ilusión te hará, es la preciosa muñeca TERESIN. ¡Sólo cuesta 85 pesetas! Cierra los ojos, llora, y además podéis comprar muchos trajes. Si no tienes ahorros para comprarla, pídeselos a los abuelos, a la madrina, o a los Reyes Magos. Pídela a tu Consejo Diocesano o bien a Tin... Tan...» (Almanaque Tin... Tan..., 1954, 3). Mariló, la muñeca de Mis Chicas había costado en 1943, 88 pesetas, y Anita Diminuta, jnada menos que 160!. 
En las primeras épocas ${ }^{88}$ Tin ... Tan... incluyó escasas historietas y muy poco humor gráfico, siendo el grueso de la misma textos didácticos, relatos, ilustraciones y pasatiempos. Después de esos primeros años (1951-1953) en los que era un cuadernillo básico de ocho hojas, fue creciendo tanto en contenidos como en calidad hasta llegar a la última época en la que pretendió acercarse al formato de una revista comercial para nińas.

\section{BAZAR Y TIN... TAN...}

Aunque las dos revistas estaban dirigidas a una misma población -infantil femenina- y defendían un modelo donde el «espacio natural femenino» era el hogar, existían unas claras diferencias entre las publicaciones. Bazar fue una revista política que nació con un marcado carácter pedagógico-adoctrinador, mientras que Tin... Tan... fue una publicación confesional.

La revista Bazar contó, desde su nacimiento, con mayores medios y pretensiones ${ }^{89}$ que el sencillo cuaderno de Tin... Tan..., que constaba de modestas colaboraciones y dibujos muy esquemáticos e infantiles. Nada tuvieron que ver con la calidad técnica y artística de los de Bazar.

Respecto a la clase social acomodada de las niñas a las que iban dirigidas las revistas, podemos decir que se evidenciaba más en Bazar. Una revista cara en la que aparecían frecuentes colaboraciones y reportajes de prestigiosos y colegios religiosos, o se deslizaba algún mensaje paternalista con las clases sociales «inferiores»:

¿Crees, acaso, que la mujer que barre la escalera, la que vende castañas en la esquina o la que lava la ropa son seres inferiores? Son como tú, pequeńa; no debes mirarles por encima del hombro porque tengas mejor posición social. Dios les ha dado un alma como a ti, pero la suerte ha sido mejor contigo que con ellas, por eso mismo debes tratarlas con mayor afecto,

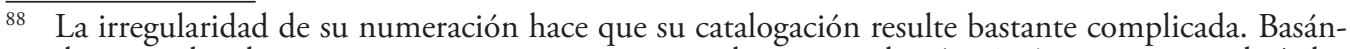
donos en los datos que tenemos intentaremos explicar su evolución: $1^{\text {a }}$ época comprendería los años 1951,1952 y 1953; 2a época 1954; 3a época 1955,1956; Año VII:1957, Año VIII:1958; Año IX:1959; Año X:1960; Año XI:1961. A partir del año 1959 la revista pasó a ser quincenal fundiéndose en 1962 con la revista para chicos Valentín para dar origen a Valentín-Tin-Tan. Inicialmente las dos palabras que componían el título de esta colección iban seguidas por puntos suspensivos, Tin ... Tan ...,que desaparecerían posteriormente pasando a denominarse simplemente Tin Tan; también aparecieron varios subtítulos a lo largo de su vida: «Niñas de A. C», "Revista de las niñas españolas», «Revista quincenal de las niñas».Tuvo tres números extraordinarios: Almanaque 1954, Almanaque 1955 y Almanaque 1956.

89 Sólo tenemos que recordar las colaboraciones de escritores como: Concha Espina, Sofía Morales, Josefina de la Maza, José Montero alonso, Gloria Fuertes, Aurora Díaz Plaja, etc. y de ilustradores como: Penagos, Serny, José Picó, Carlos Tauler, Chummy y otros. Y que, incluso, en 1947 los personajes de la revista Bazar fueron llevados al Teatro Cómico por la compañía de Jardiel Poncela en una revista del mismo nombre (Bazar, octubre1947, núm.8, 21). 
empleando siempre palabras agradables para las personas de inferior posición social ${ }^{90}$.

También aparecían frecuentemente los cuentos de niñas pobres, que tenían que hacer penosos trabajos para poder subsistir, a las que se les aparecía un maravillo príncipe que, prendado de su humildad, bondad y belleza, se casaba con ellas.

Las lectoras de Tin... Tan..., aunque la revista fuese más modesta, tampoco pertenecían a la clase media baja o a la baja; mas bien se trataba de niñas pertenecientes a familias de la clase media con un mayor nivel cultural y económico, como lo demostraba el tipo de correspondencia que mantenían, el contenido socio-cultural de sus artículos o el precio de la muñeca «oficial» de la revista.

Respecto al estilo de las revistas cabe decir que Bazar tenía secciones de carácter «oficialista» o propagandístico que mostraban la «manera de ser» de la Sección Femenina, mientras que Tin... Tan... presentaba unos contenidos más infantiles o incluso «ñoños»-en terminología falangista-.

En la época existieron otros tebeos comerciales para niñas, dirigidos a la clase popular como Azucena (1946), Ardillita (1949) y Margarita (1951). En 1949 nació Florita que se convirtió en el tebeo femenino para las chicas de las clases medias ${ }^{91}$.

Los tebeos políticos y confesionales tuvieron que competir con los tebeos comerciales, obligándoles a remodelar y modernizar sus formatos y contenidos. De esa manera, tanto Bazar como Tin... Tan... fueron acercándose a lo largo de su vida a los modelos comerciales. Pero algo incontestable es que a través de las dos revistas se orientó a sus lectoras hacia la práctica de normas sociales consideradas propias del ámbito femenino que tenían que ver con lo doméstico y el cuidado de los otros.

Así, estas publicaciones no formales actuaron en la España franquista como complemento de los textos escolares, contribuyendo a la socialización de las niñas en la diferencia entre los sexos.

Las niñas aprendieron a lo largo de sus páginas a creer en Dios y en la Patria. A rezar todas las noches. A cocinar, coser y cantar. A ser buenas y caritativas, cuidar de sus hermanitos y guardar su pureza como una flor delicada. A sońar con ser madre, imaginar

90 «Lo que una niña debe hacer», Bazar, marzo 1947, núm.3, 7.

91 Véase RAMÍREZ, J. A., El « comic» femenino en España, Madrid, Cuadernos para el Diálogo, 1975, 59-63; VÁZQUEZ DE PARGA, S., Los comics del franquismo, Barcelona, Planeta,1980,228-229; MOIX, T. R., Los «comics» arte para el consumo y formas pop, Barcelona, Llibres de Sinera, 1968, 134-138; CONDE MARTÍN, L., «Florita», Trinca, núm.64 (1973) 9. Puede consultarse el estudio de MUNOZZ RUIZ, C., «Florita: un tebeo para las jovencitas de las clases medias en la España franquista», Tiempos de silencio. Actas del IV Encuentro de Investigadores del franquismo, Universitat de València, Valencia, 1999, 668-673, (Ilustración 10). 
viajes irrealizables o ser misionera. A esperar a un príncipe valiente, no leer libros ni ver películas prohibidas. A amar a las muñecas. Pero quizá, por encima de todo, el aprendizaje más importante fue el de guardar silencio y obedecer. 


\section{ILUSTRACIONES}

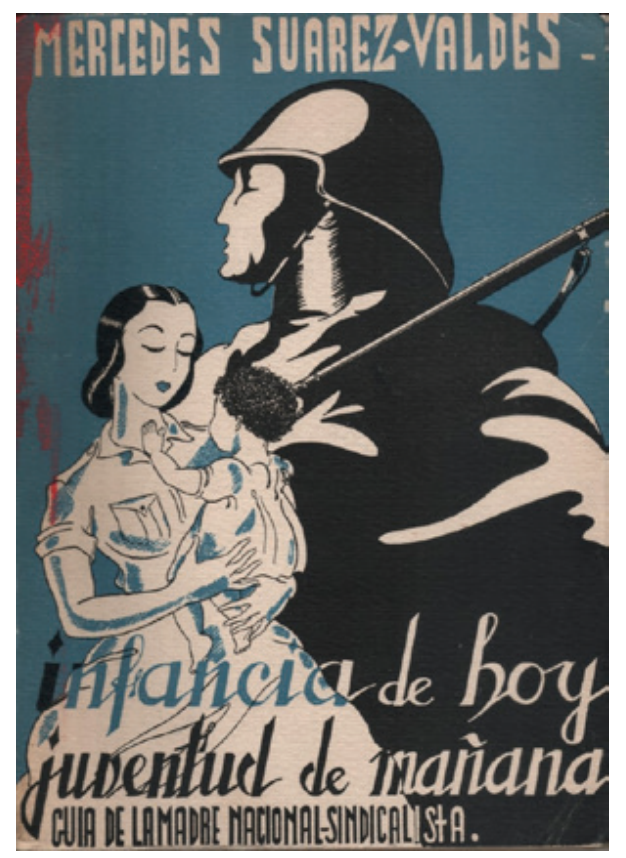

1. Infancia de hoy... (1940)

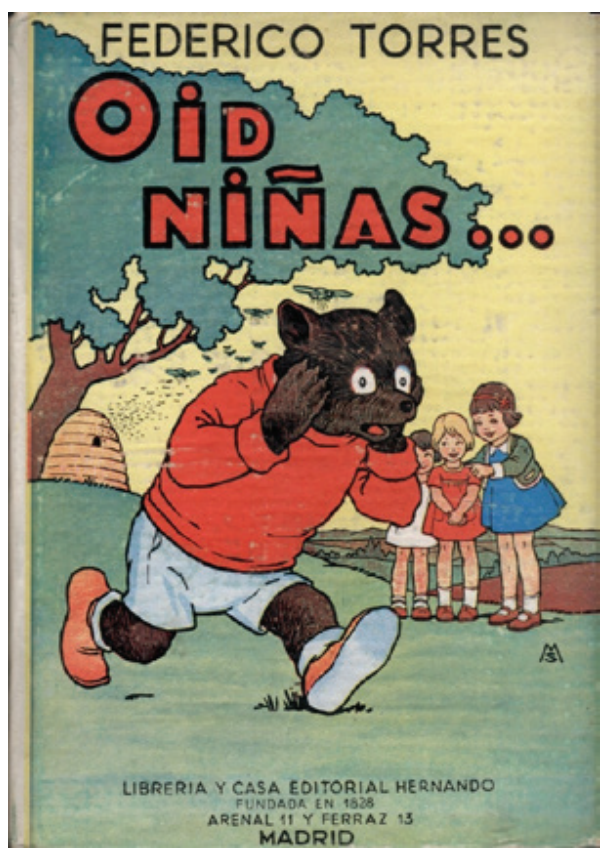

3. Oid niñas... (1957)

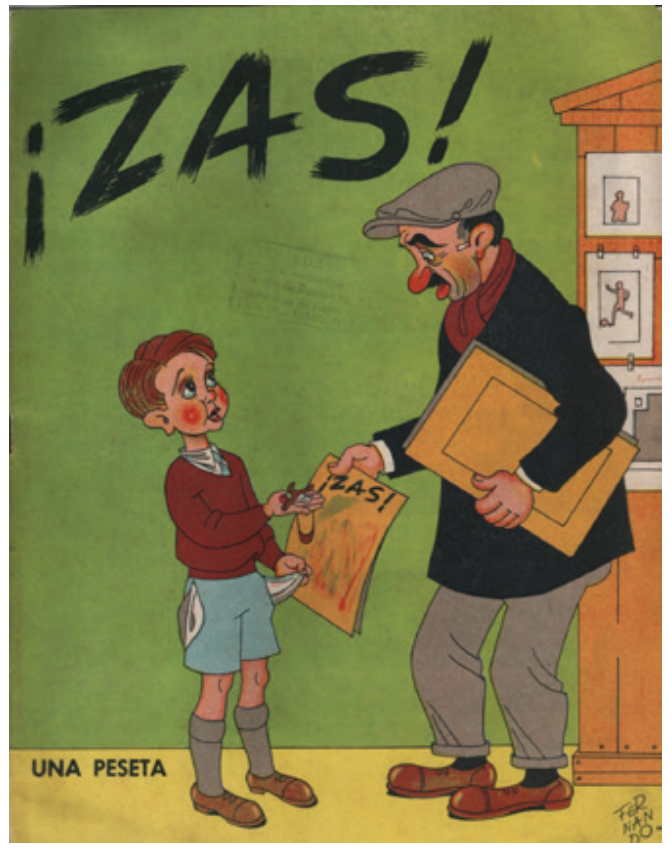

2. ¡Zas! (1945)

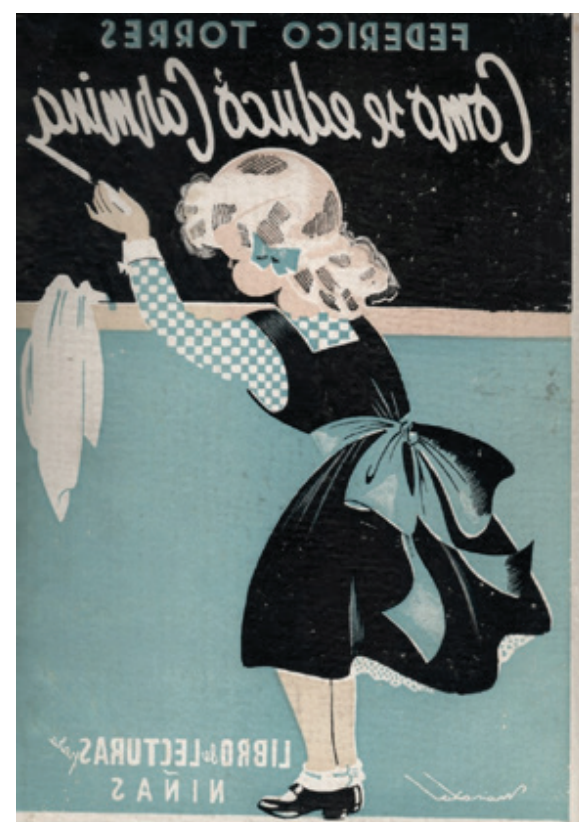

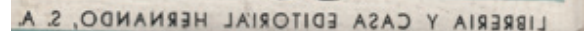

4. Cómo se educó Carmina (1953) 


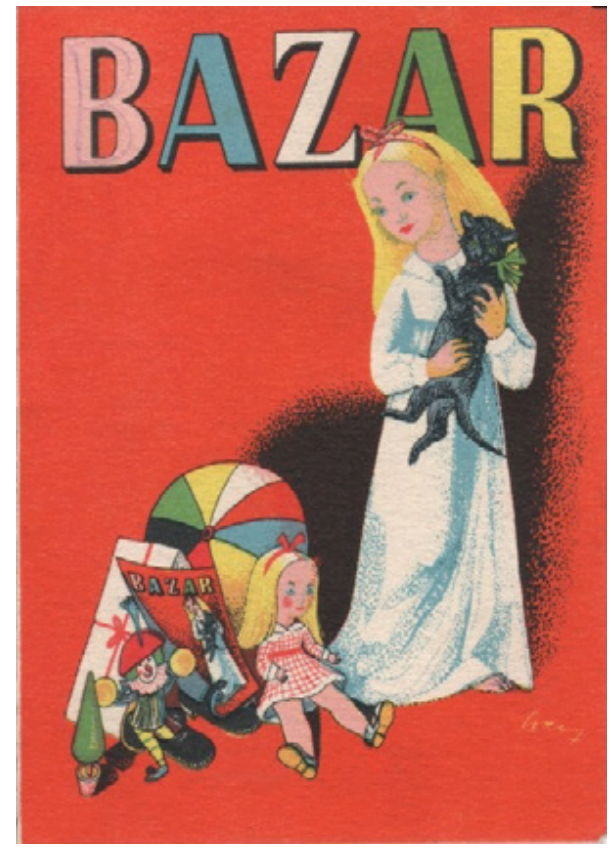

5. Bazar (1947)

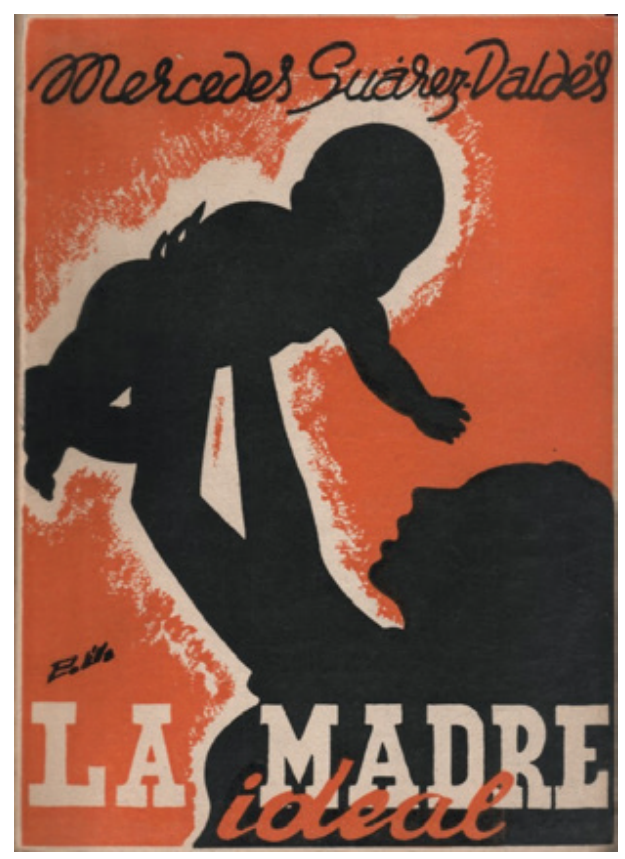

6. La madre ideal (1951)

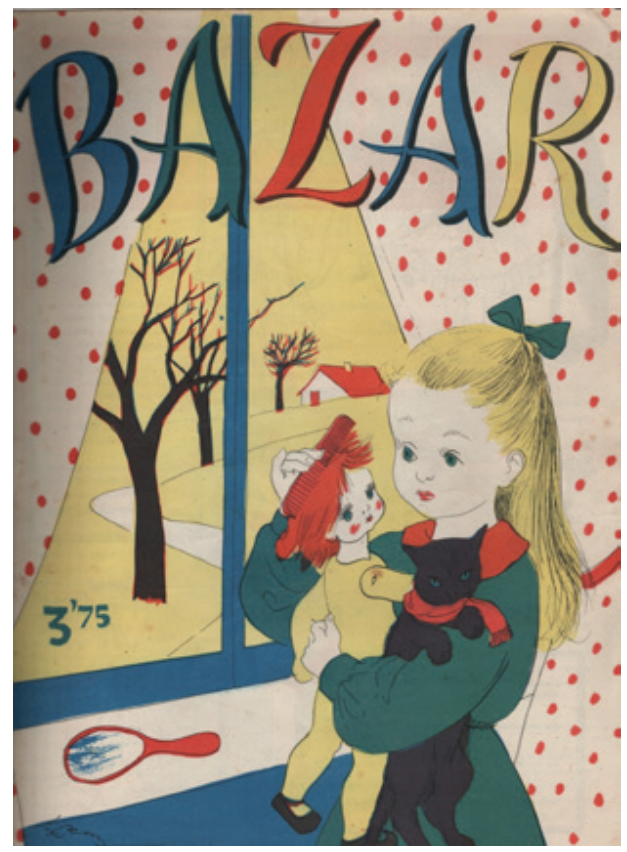

El Futuro del Pasado, no 4, 2013, pp. 227-253

ISSN: 1989-9289 


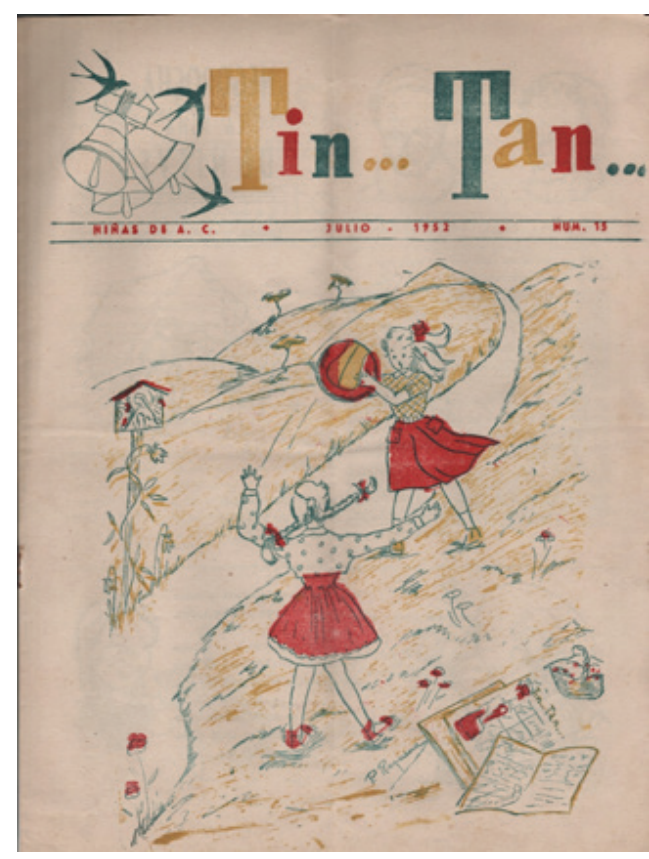

8. Tin... Tan... (1952)

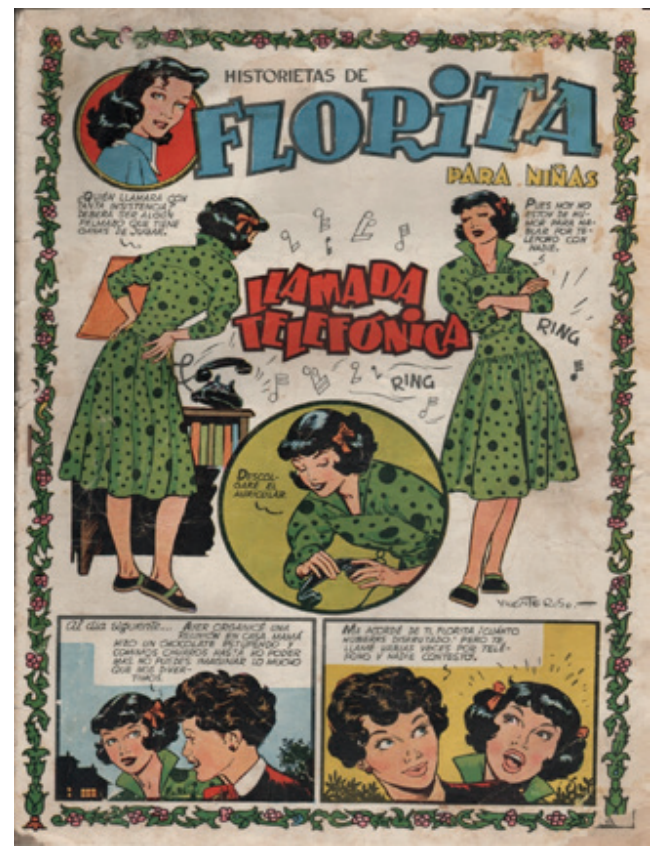

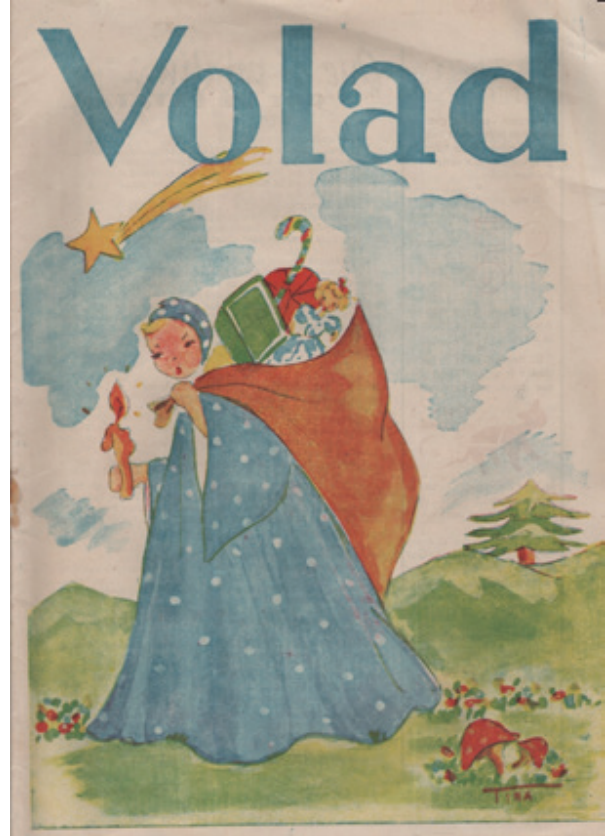

9. Volad (1949)

10. Florita (1949) 